\title{
A AÇÃO AMBIENTAL DAS ORGANIZAÇÕES JUNTO AOS SEUS STAKEHOLDERS
}

\section{THE ORGANIZATION ENVIRONMENTAL ACTION IN THE DIRECTION OF THEIR STAKEHOLDRS}

\author{
Celso Machado Junior ${ }^{1}$; Maria Tereza Saraiva de Souza ${ }^{2}$; Cristiane Jaciara Furlaneto ${ }^{3}$; \\ Leonel Mazzali ${ }^{4}$; João de Paula Ribeiro Neto ${ }^{5}$ \\ ${ }^{1}$ Universidade Municipal de São Caetano do Sul - USCS - São Caetano do Sul - Brasil \\ celsomachado1@gmail.com \\ ${ }^{2}$ Universidade Nove de Julho - UNINOVE - São Paulo - Brasil \\ mtereza@uninove.br \\ ${ }^{3}$ Universidade Municipal de São Caetano do Sul - USCS - São Caetano do Sul - Brasil \\ crisjaciara@ig.com.br \\ ${ }^{4}$ Universidade Municipal de São Caetano do Sul - USCS - São Caetano do Sul - Brasil \\ leonel_mazzali@uol.com.br \\ ${ }^{5}$ Universidade Municipal de São Caetano do Sul - USCS - São Caetano do Sul - Brasil \\ joão.ribeiro@uscs.edu.br
}

\begin{abstract}
Resumo
A preocupação ambiental se apresenta como um tema presente nas discussões e reflexões da sociedade, dos poderes públicos e das organizações. A sensibilização e o entendimento da importância do meio ambiente pela sociedade, demanda a necessidade de ações que propiciem um conjunto de conhecimento referente a esta temática. Assim se destaca a importância da educação ambiental como componente de conformação de uma sociedade que incorpora a dimensão ambiental, com as bases econômicas regidas pela sustentabilidade. Nesse contexto o objetivo dessa pesquisa é verificar se as empresas com Sistema de Gestão Ambiental, certificadas com a NBR ISO 14001, incorporaram os stakeholders na gestão empresarial de forma mais acentuada que as empresas não certificadas pela norma ambiental. Trata-se de uma pesquisa descritiva, assentada em uma amostra composta por 649 empresas, que disponibilizaram informações para a publicação na revista Análise Gestão Ambiental (2008). A utilização de tratamento estatístico evidenciou que as empresas certificadas pela norma NBR ISO 14001 demonstraram a presença de um conjunto maior de fatores ambientais voltados para os Stakeholders.
\end{abstract}

Palavras-chave: educação ambiental; gestão ambiental; ISO 14001; meio ambiente; stakeholders.

\section{Introdução}

A preocupação ambiental se configura como tema presente na sociedade, nos poderes públicos e nas organizações e manifesta-se mais claramente na necessidade de preservação do meio ambiente e na perpetuação de fontes de recursos para a manutenção da sociedade e das operações nas organizações. Esse movimento tornou-se perceptível no fim do século XX, mais precisamente a 
partir da década de 1970, com a mudança de foco que antes restringia-se apenas nas operações diárias das organizações para incluir a sociedade como um todo para a importância da sustentabilidade dos recursos. Segundo Seiffert (2005) e Barbieri (2007), somente nas três últimas décadas do século XX, os aspectos ambientais passaram a ser debatidos em profundidade. A Conferência Mundial sobre o Meio Ambiente, realizada em 1972 na cidade de Estocolmo, constituiu um importante marco dessa nova fase.

O aprofundamento da discussão sobre a importância do meio ambiente envolvendo as empresas, o governo e a sociedade civil como um todo ganhou destaque na ECO-92 (CNUMAD), promovida pela United Nations Conference on Environment and Development (UNCED) na cidade do Rio de Janeiro. O resultado final dessa reunião foi a elaboração da Agenda 21, que tornou-se referência na implantação de programas e políticas de preservação do meio ambiente. Destaca-se que esse conjunto de fatores influenciou empresas a incluir as variáveis ambientais em seu conjunto de ações de decisões organizacionais (ROSEN, 2001; SEIFFERT, 2005).

Outros eventos de destaque ocorreram em Kyoto, em 1998, nos quais o impacto das emissões gasosas no meio ambiente ocupava o centro das discussões, e em Johanesburgo (Rio + 10), em 2002, na Conferência das Nações Unidas sobre o Ambiente e Desenvolvimento Sustentável. O Painel Intergovernamental de Mudança do Clima (IPCC), que ocorreu em 2007 em Paris, vinculado ao programa das Nações Unidas para o meio ambiente (PNUMA) e a Organização de Meteorologia Mundial (OMM), enfatizou na publicação do seu resumo a influência das atividades humanas no processo de alterações climáticas, bem como o agravamento verificado desde o levantamento anterior realizado em 2001.

A identificação de um conjunto amplo de problemas sociais e ambientais impõe a necessidade de abordagens sistêmicas e integradas que incorporem várias disciplinas e seus universos de conhecimento para suportar as demandas concernentes às relações de trabalho, aos processos de produção e consumo, à saúde dos indivíduos e ao meio ambiente (FRANCO, 2002).

Há uma complexa relação que se estabelece entre os atores ambientais e a sinergia entre eles, com um conjunto de causa e efeito que emana entre as partes. Nesse cenário, se inserem as relações sociais contextualizadas nos stakeholders, que incluem indivíduos, grupos e outras organizações que têm maior inter-relação com o processo de gestão e influenciam em suas decisões. A contextualização dos Stakeholders no sistema de gestão da organização amplia o universo de atores que influenciam na elaboração de sua estratégia, bem como nas suas decisões diárias. Nesse contexto, o paradigma focado apenas no lucro, que sustentava as ações do gestor, se expande para atender outros fatores, entre os quais o ambiental e o social.

O fator ambiental se incorporou no escopo de questões de atenção da humanidade, conforme demonstram os relatórios ambientais da Organização das Nações Unidas (ONU), com o despertar 
para a urgência e importância dos efeitos da mudança climática no ambiente e na sociedade. Nessa nova realidade, os consumidores locais ou globais adquirem poder de pressão sobre uma empresa para que adote medidas ambientais responsáveis.

Um reflexo do desenvolvimento da consciência ambiental da sociedade é a inserção da Educação Ambiental nos currículos escolares. A primeira Conferência Intergovernamental sobre Educação Ambiental, realizada em 1977, em Tbilisi na Geórgia, posicionou a Educação Ambiental como um processo permanente, de aquisição de conhecimento, valores, habilidades e experiências objetivando capacitar os indivíduos e a coletividade a resolver os problemas ambientais presentes e futuros. Dias (1992) assevera essa posição destacando que o processo de Educação Ambiental deve promover a consciência do meio ambiente nos indivíduos e na comunidade, e as dimensões sociais, políticas, econômicas, culturais, ecológicas e éticas devem estar voltadas aos esforços destinados a solução de seus problemas. Dessa forma, os impactos decorrentes das atividades econômicas das empresas estarão inseridos no contexto destinado a solucionar o problema enfrentado por determinada comunidade.

Para Ferreira (2005), a industrialização trouxe para as cidades um aumento significativo de pessoas, impactando negativamente tanto nos fatores sociais quanto nos ambientais, ou seja, os benefícios econômicos advindos da atividade econômica da empresa não apresentaram apenas resultados positivos. Nesse sentido, a autora destaca ser essencial que as políticas públicas estejam voltadas para eliminar ou mitigar esses impactos, salientando a importância do município apresentar legislações que tenham como finalidade suportar tais demandas. Esse cenário configura a importância da empresa no meio ambiente e na sociedade que a circunda, ao mesmo tempo em que incorpora todas as esferas do poder público.

Para Barbieri (2007), o estágio evolutivo da gestão ambiental se constitui em um processo contínuo, composto por um conjunto de fases, que é passível de implantação gradual mediante práticas apropriadas. Assim sendo, a empresa pode se posicionar não somente quanto ao êxito obtido até determinado momento, mas também quanto ao que ainda falta para atender um estágio considerado adequado pelo poder público e pela sociedade. Destaca-se que as demandas envolvendo o meio ambiente ainda estão em fase de construção, de tal forma que a empresa considerada madura em seu processo de gestão ambiental, pode apresentar deficiências mediante as novas condições jurídicas ou sociais, caracterizando-se assim o estabelecimento de uma nova fase a ser atendida, marcando o dinamismo que deve marcar a gestão ambiental.

Essa dinâmica reforça o entendimento da intensa troca de energia entre a empresa e o meio ambiente, beneficiando a discussão das questões ambientais na gestão empresarial. Assevera-se, assim, a necessidade de uma gestão com práticas voltadas a atender essa nova demanda que contemple a avaliação sistêmica e sustentável de impactos decorrentes da realização das atividades. 
Nesse contexto, a certificação pela norma NBR ISO 14001 (Sistemas de gestão ambiental requisitos com orientação para o uso) vem se estabelecendo como uma atrativa alternativa, por contemplar um conjunto de requisitos norteadores da incorporação da variável ambiental na gestão das organizações. O benefício da emissão de certificado de atendimento à norma por organismos independentes possibilita que a sociedade visualize a preocupação ambiental. Essa certificação demanda a necessidade de auditorias periódicas de manutenção da certificação, garantindo a aderência da organização à norma e aos requisitos legais, de forma perene.

Se a certificação da organização possibilita a adoção de um modelo de gestão apoiado na transparência das ações e na garantia de atendimento legal, evidencia-se a necessidade de análise da conduta das empresas certificadas no processo de Educação Ambiental dos stakeholders. Dessa forma, o objetivo dessa pesquisa é verificar se as empresas com Sistema de Gestão Ambiental, certificadas com a NBR ISO 14001 e as de maior porte incorporam, de forma mais acentuada, os stakeholders na gestão empresarial do que as que não são certificadas pela norma ambiental e as de menor porte.

Trata-se de pesquisa descritiva, assentada em uma amostra composta por 649 empresas de diferentes ramos de atividade, que disponibilizaram informações para a publicação na revista Análise Gestão Ambiental (2008). Por meio desse estudo verificam-se algumas variáveis das empresas que compõem a amostra de pesquisa, porém possibilita distinguir as empresas em dois grupos de atenção: as que possuem Sistema de Gestão Ambiental, certificado pela norma NBR ISO 14001 e as não certificadas. O ponto central e a hipótese desse estudo é uma expectativa natural das empresas certificadas possuírem uma gestão que incorpore práticas que contemplem, de forma mais acentuada, os stakeholders como medida necessária para um desenvolvimento sustentável e, de forma complementar, que as empresas de maior porte também deem a mesma atenção. Dessa forma, o ponto central desse estudo se estrutura no entendimento se as empresas certificadas pela norma NBR ISO 14001 apresentam maior atenção para a gestão dos stakeholders.

\section{Referencial teórico}

A questão ambiental possui a essência de se fazer presente em todas as atividades da sociedade, logo não deve ser analisada de forma estanque a luz de limites predeterminados. Dessa forma um conjunto de conhecimentos deve ser aglutinado para servir de base para análises concernentes à solução dos problemas que se apresentam para a sociedade. Nesse estudo, pontuamos a Educação Ambiental, como componente tanto de modificação da sociedade quanto para capacitar o indivíduo a resolver os problemas ambientais. Nesse contexto, a certificação pela Norma NBR ISO 14001 estabelece os componentes dos padrões de gestão empresarial voltados à questão ambiental nas organizações. E finalmente o stakeholder que se configura, de forma macro, 
como a parcela da sociedade que irá atuar, de forma ativa, com a empresa, seja por ameaça, seja por cooperação.

\subsection{A educação ambiental e seus desafios}

O estágio da consciência ambiental e social na organização, como já destacado, teve início na década de 1970, por meio de conferências e eventos internacionais que agregaram poder público, tanto à sociedade quanto às empresas. Era uma causa comum que necessitava da participação coletiva para o atendimento da demanda que surgia. A ênfase e a expansão da preocupação ambiental posicionam o ser humano no centro da possibilidade de uma terrível ameaça à natureza.

A Educação Ambiental é inserida no sistema educacional para capacitar o educando a ampliar sua percepção sobre o meio ambiente, tornando-o capaz de atuar a serviço da comunidade nos processos de solução de seus problemas. A Educação Ambiental se destacou no cenário mundial após a conferência de Tbilisi, retornando a discussão em vários outros encontros promovidos por organismos voltados à área ambiental e educacional.

Em decorrência dos eventos internacionais, o Brasil inicia o processo de incorporação da Educação Ambiental em seu sistema de ensino. No contexto Brasileiro dois eventos são marcos nesse processo. O primeiro é a própria Constituição Federal (1988), que, no artigo 225, insere o direito ao meio ambiente adequado e que possibilita qualidade de vida à sociedade, para tanto o poder público e a sociedade devem atuar de forma a defendê-lo e a preservá-lo no presente e para as gerações futuras. A Educação Ambiental deve ser promovida em todos os níveis de ensino, com destaque para a conscientização pública a respeito da preservação do meio ambiente. O segundo é a Lei /99 - Política Nacional de Educação Ambiental, que insere o indivíduo como agente transformador e responsável pela qualidade e sustentabilidade da vida no planeta, saindo da condição de mero expectador.

Em princípio, a incorpora, além da concepção de meio ambiente, aspectos socioambientais, culturais e éticos. Para tanto, o tema ambiental deve ser incorporado ao projeto pedagógico e tratado de forma transversal e interdisciplinar e não como mera disciplina isolada do contexto social. A Lei 199, aborda ainda a Educação Ambiental Não Formal que consiste de ações e práticas educativas voltadas à manutenção da qualidade do meio ambiente, por parte das empresas públicas e privadas, no desenvolvimento de programas de Educação Ambiental. Nesse sentido, a certificação pela norma NBR ISO 14001 pode se integrar ao processo de conscientização e sensibilização de seus stakeholders para as questões ambientais.

A Educação Ambiental está dividida em dois momentos no sistema de ensino. O primeiro, no ensino fundamental, que objetiva a sensibilização dos alunos para os problemas e potencialidades ambientais, instigando-os a desenvolver a capacidade de investigar, descobrir e 
compreender o mundo que os rodeia, possibilitando assim o entendimento de algumas inter-relações simples entre fenômenos naturais e sociais. No Ensino Médio, o aluno é inserido no contexto de projetos de intervenção socioambiental e comunitário, evidenciando as ações responsáveis e participativas.

No entanto, a Educação Ambiental concorre com um modelo de vida contemporânea que incentiva o consumismo. Esse apelo do consumismo se constitui em um grande obstáculo para a incorporação da importância das questões ambientais na sociedade, o que gera um questionamento em relação à efetividade da Educação Ambiental nas escolas. Para Serrano (2003), as escolas não estão logrando êxito no processo de mudança de valores e atitudes, que resultem em uma sociedade que pratique o consumo ambientalmente correto. Os alunos, em geral, não incorporam os comportamentos desenvolvidos na Educação Ambiental, tanto que suas atitudes demonstram a continuidade de aquisições de produtos norteada pela satisfação pessoal, e a continuidade de hábitos que não priorizam a conservação dos recursos naturais, estabelecendo um descompasso entre teoria e prática.

Essa dinâmica possibilita ao aluno maior envolvimento nos processos de transformação da sociedade. Vale destacar que esse aprendizado vai ao encontro do atendimento das necessidades que os indivíduos se defrontaram na vida profissional, pois as organizações necessitam de colaboradores que atuem nos problemas e impactos gerados em decorrência de suas atividades.

\subsection{A importância da certificação pela norma NBR ISO 14001}

As empresas possuem uma importante parcela de responsabilidade no objetivo de alcançar o desenvolvimento sustentável. Segundo Slack et al (2002), a magnitude do impacto ambiental possui uma relação direta com a parcela consumidora da população, os processos produtivos e os produtos que consomem. Dessa forma, as empresas se deparam com novas exigências de seus clientes, em que os fatores ecológicos passam a ser determinantes no momento da compra de um produto ou serviço.

Para Rohrich e Cunha (2004), a gestão ambiental está relacionada ao conjunto de políticas e práticas operacionais e administrativas que incorporam o contexto amplo da empresa e da sociedade. Tal conjunto inclui a saúde e a segurança das pessoas, bem como a proteção do meio ambiente pela eliminação ou mitigação de impactos e danos ambientais advindos do planejamento, implantação, operação, ampliação, realocação ou desativação de empreendimentos ou atividades. Incluem-se aí todas as fases do ciclo de vida do produto. Os autores ressaltam a importância do meio ambiente não somente sobre as bases econômicas, mas também sobre a saúde pública.

Segundo Maimon (1994), a pressão da sociedade, no âmbito do meio ambiente, é atendida pelas empresas em três estágios: a) instalação de equipamento de controle de poluição nas saídas, 
sem alterar a estrutura produtiva ou o produto; b) modificação de processos e/ou produtos para atender à regulamentação ou exigências do mercado concernentes à questão ambiental, a fim de prevenir a geração de poluição e problemas que prejudiquem a consecução da estratégia empresarial e c) adoção de um comportamento proativo e de busca pela gestão sustentável, antecipando-se aos problemas ambientais futuros, cujo princípio é incorporar as variáveis ambientais ao planejamento estratégico.

A gestão das organizações se caracteriza por uma diversidade de posturas, desencadeando diferentes graus de desenvolvimento e comprometimento com as questões ambientais. Segundo Barbieri (2007), o primeiro estágio é denominado de controle da poluição, restrito ao cumprimento da legislação ambiental e ao atendimento das pressões da comunidade. No segundo estágio, denominado integração preventiva, o foco se concentra na utilização eficiente dos insumos, com a abordagem ambiental se expandindo da área manufatureira para o conjunto da organização. No último estágio, a abordagem ambiental é incorporada à estratégia da organização.

A inclusão da questão ambiental na estratégia organizacional pode, em um primeiro instante, significar a incorporação de uma variável agregadora de problemas e geradora de gastos, mas uma análise mais detalhada possibilita desvendar um universo de potenciais ganhos, com destaque para: a) novas fontes e formas de financiamento, disponibilizadas para a incorporação de melhorias ambientais nas empresas; b) ganho de eficiência e, por consequência, redução de custos, com a melhor utilização dos recursos empregados no processo produtivo; e c) obtenção de vantagens competitivas, por meio da captação de clientes preocupados com o meio ambiente no momento de escolha do produto e/ou fornecedor.

Nesse contexto, Donaire (1999) destaca que, entre as diferentes variáveis que afetam o dinâmico ambiente de negócios, a preocupação ecológica, de forma crescente, vem adquirindo relevância em relação a qualidade de vida das populações. Vale destacar que a visibilidade das ações da organização aumentou com o advento da revolução da informação, proporcionado pela internet, com a maior conscientização ambiental, com a promulgação de leis e normas ambientais e, de modo particular, com a adesão do Brasil aos acordos e aos tratados internacionais.

O plano estratégico e a arquitetura organizacional devem consolidar a abordagem socioambiental a fim de claramente expressar os objetivos, as ações de mitigação do aquecimento global e o grau de mobilização dos agentes internos e externos, caracterizados pela cadeia na qual a empresa se insere. As empresas possuem produtos, processos e culturas próprios, logo a estratégia de inovação estará marcada por essas variáveis, e mesmo ante a opção de aquisição de soluções já existentes no mercado, elas serão objeto de adaptação à realidade organizacional, desencadeando assim inovações e aprendizado.

Em decorrência da natureza contemporânea das variáveis ambientais, as organizações se 
deparam com o desafio de incorporar em seu modelo de gestão protocolos e condutas que atendam a essa nova realidade. Ante a necessidade de ajustar e ou alterar suas atividades, um caminho natural é a adoção de modelos de gestão estabelecidos especificamente para essa situação. Entre as alternativas, destaca-se o modelo expresso na norma NBR ISO 14001, incluindo uma abordagem sistêmica, voltada ao equacionamento dos interesses econômico-financeiros com os impactos ambientais gerados pelas atividades da organização. Ao lado de condutas e ferramentas para a gestão ambiental, a norma impulsiona a adequação das instalações e a redução dos impactos decorrentes das atividades.

Bezerra e Abreu (1994) destacam a importância da norma BS 7750 - Especification for Environmental Management Systems, promulgada em 1992 pela British Standards Institution BSI. Essa norma foi precursora na área de normatização de sistemas, inclusive a ambiental, influenciando a criação da norma internacional ISO 14001, incorporada pela Associação Brasileira de Normas Técnicas (ABNT) com a sigla NBR ISO 14001 - Sistema de Gestão Ambiental (2004). Vale destacar que, nesse período, a grande diversidade de normas configurava um cenário que poderia comprometer o comércio internacional. Em decorrência dessa possibilidade, em 1993 criouse o Technical Committee 207 (TC-207) para formular a série de normas da ISO 14000. Esse comitê é composto por seis subcomitês, os três primeiros dizem respeito a normas aplicadas à organização - gerenciamento, auditoria e desempenho ambiental - e os três outros grupos referem-se a normas aplicadas a produtos - avaliação do ciclo de vida, rotulagens e padrões ambientais.

A série de normas NBR ISO 14000, que contém a norma NBR ISO 14001, foi criada com o objetivo de estabelecer estruturas e procedimentos voltados à melhoria contínua do desempenho ambiental. A adoção dessa norma demanda uma mudança cultural na organização, que se compromete com o esforço de melhoria ambiental contínua e com a redução dos impactos decorrentes da execução das atividades.

Entre os requisitos do Sistema de Gestão Ambiental, como pode ser visto no Quadro 1, a adoção da norma NBR ISO 14001 demanda treinamento dos funcionários, implantação de programas e sistemas de comunicação ambiental, definição de padrões internos, reformulação dos processos produtivos e dos equipamentos de proteção ambiental. Um sistema de gestão ambiental, baseado na norma NBR ISO 14001, requer o comprometimento da empresa com seu regulamento ambiental e um sistema de padronização de procedimentos que abrange o conjunto da organização.

Quadro 1: Requisitos do Sistema de Gestão Ambiental da Seção 4 da norma NBR ISO 14001: 1996.

\begin{tabular}{|l|l|l|}
\hline 4.1 Requisitos gerais & 4.4 Implementação e operação & 4.5 Verificação e ação corretiva \\
& 4.4.1 Estrutura e responsabilidade & 4.5.1 Monitoramento e medição \\
4.2 Política Ambiental & 4.4.2 Treinamento, conscientização e & 4.5.2 Não conformidade e ações \\
& competências. & corretivas e preventivas \\
4.3 Planejamento & 4.4.3 Comunicação & 4.5.3 Registros \\
4.3.1 Aspectos ambientais & 4.4.4 Documentação do SGA & 4.5.4 Auditorias do Sistema de \\
4.3.2 Requisitos legais e outros & 4.4.5 Controle dos documentos & Gestão ambiental \\
\hline
\end{tabular}




\begin{tabular}{|l|l|l|}
\hline $\begin{array}{l}\text { 4.3.3 Objetivos e metas } \\
\text { 4.3.4 Programa(s) de gestão } \\
\text { ambiental }\end{array}$ & $\begin{array}{l}\text { 4.4.6 Controle operacional } \\
\text { 4.4.7 Preparação e atendimento de } \\
\text { emergência }\end{array}$ & $\begin{array}{l}\text { 4.6 Análise crítica pela } \\
\text { administração }\end{array}$ \\
\hline
\end{tabular}

Fonte: adaptado da ABNT (1996)

A norma NBR ISO 14001 (ABNT, 1996) determina que todos os funcionários, cujas tarefas possam criar impacto significativo sobre o meio ambiente, recebam treinamento apropriado. Além disso, a norma recomenda que os prestadores de serviços sejam capazes de demonstrar que seus empregados tenham treinamento requerido. Para Barbieri (2007), os programas de treinamento e conscientização devem avançar no sentido de promover mudanças de comportamento diante das questões ambientais mais amplas que as relacionadas com a atuação da empresa.

Segundo Fryxell e Szeto (2002), os possíveis benefícios advindos de certificação pela norma são: adequação às conformidades regulatórias, redução de custos advindos de melhor utilização dos recursos, atendimento às expectativas dos clientes e da sociedade e melhora na reputação corporativa. Zeng et al. (2005), ampliam esse escopo incluindo os seguintes benefícios: qualificação para entrada no mercado internacional, universalização dos procedimentos de gestão ambiental com os protocolos das operações internas, redução de desperdícios do gerenciamento corporativo e aumento na consciência ambiental de fornecedores.

A norma NBR ISO 14001 se constitui, portanto, em um fator que pode influenciar na estrutura da organização, se configurando como elemento de diferenciação entre as empresas, na abordagem da gestão ambiental.

\subsection{Stakeholders, a incorporação da sociedade na organização}

As organizações possuem um amplo conjunto de interfaces com a sociedade, que, de um lado, são afetadas pela realização de suas atividades econômicas, por outro, são agentes de pressão sobre seu comportamento. Conforme Savage et al. (1991), os stakeholders de uma organização se compõem de indivíduos, grupos e outras organizações que têm interesse em suas ações bem como habilidade para influenciá-la. Tapscott e Ticoll (2005) destacam que muitas empresas que negligenciaram os grupos que influenciam suas atividades foram acometidas de graves problemas, ou em situações mais críticas devastadas ou destruídas.

A diversidade do rol de interfaces não possibilita que a empresa dedique a mesma atenção a todos stakeholders, porém a sua gestão deve estar atenta aos que possuem maior relevância, para tanto concorrem fatores econômicos, ambientais, sociais, legais, entre outros. Essa hierarquização não objetiva diminuir a importância de determinados grupos em relação aos demais, mas sim possibilitar o máximo de eficiência na solução dos problemas mais relevantes. Dessa forma, sua estratégia deve contemplar tanto problemas atuais quanto os potenciais, se valendo para tanto de cenários nos quais os agentes externos, os stakeholders, possuem maior influencia na sua gestão. 
Assim, as empresas tendem a mapear seus stakeholders de acordo com sua respectiva influência. Nesse sentido, estudos empíricos como o de Bourne e Walker (2005) denotam a importância do uso de ferramentas específicas no processo de identificar e mapear o poder e a influência dos stakeholders nas suas atividades. O resultado desse mapeamento deve fornecer a organização dos stakeholders, foco de atenção, por ameaçar o negócio ou possibilitar cooperação mútua, evitando à implementação de estratégias e ações que se contraponham a eles. Esse processo deve reconhecer as necessidades das partes interessadas, a fim de modificar ou aprimorar os planos organizacionais e ou a estrutura social envolvida.

Savage et al. (1991) propõem a classificação dos stakeholders em quatro classes distintas: a) Dispostos a apoiar - que se caracterizam pelo baixo potencial de ameaça associado ao alto potencial de cooperação; b) Marginais - apresentam-se neutros, pois não representam ameaças e nem predisposição para cooperar; c) Indispostos a cooperar - com alto potencial de ameaça associado à baixa disposição em cooperar; d) Ambíguos - destacam-se por alto potencial tanto de ameaça quanto de cooperação.

Apesar dos stakeholders apresentarem tanto ameaça quanto potencial de cooperação, essa virtude é frequentemente ignorada por receio de compartilhamento de informações e condutas em andamento. $\mathrm{O}$ entendimento das possibilidades de cooperação com os stakeholders pela organização pode resultar em benefícios a todos envolvidos, sem a obrigatoriedade de contrapartidas financeiras pela empresa. Para Salvage et al. (1991), na maioria das vezes, quanto maior for a relação de dependência do stakeholder, maior será sua disposição em cooperar. Nesse caso, as partes envolvidas compartilham os planos a fim de eliminar os pontos divergentes, por meio do reconhecimento das necessidades e problemas existentes, em um processo contínuo de melhoria.

\section{Método de pesquisa}

A pesquisa se aprofunda na identificação do atual cenário de ações ambientais desenvolvidas para os stakeholders da organização pela análise da interface da abordagem da gestão para a conscientização e desenvolvimento ambiental. Para tanto, a investigação irá centrar-se em dois grupos de análise: o primeiro, com foco principal nas empresas certificadas pela norma NBR ISO 14001; e secundário, pelo porte da empresa.

A linha de atuação do projeto se classifica como uma pesquisa descritiva, assentada em dados secundários. Segundo Cervo, Bervian e Silva (2007), as pesquisas descritivas têm o objetivo de propiciar maior entendimento sobre a frequência com que um fenômeno ocorre, sua correlação e conexão com outros fenômenos. 
A amostra é composta por 649 empresas que disponibilizaram suas informações para a publicação na revista Análise Gestão Ambiental (2008). A revista em questão realizou, durante 2008, um trabalho de quatro meses envolvendo 20 profissionais no processo de distribuir e captar questionários, com posterior análise de consistência dos dados e preparo para publicação. A revista realizou as totalizações das respostas, porém não estabeleceu estudos ou análises, objetivando identificar correlações entre os dados obtidos. Dessa forma, por meio desse estudo, constrói-se uma nova tabela com os dados secundários disponibilizados para, posteriormente, realizar-se as análises estatísticas pertinentes ao objetivo proposto. Vale destacar que os questionários foram encaminhados e respondidos diretamente pelas empresas, por meio de seus representantes legais.

Os dados a serem utilizados se configuram como secundários. Vale destacar que a obtenção de dados disponíveis em publicações não diminui a importância da pesquisa. Para tanto é importante diferenciar o que é conhecimento do que é informação. Enquanto a informação se constitui como um artigo ou objeto de uso comum, que é capaz de produzir conhecimento, o conhecimento, por sua vez, é identificado como a informação processada ou sustentada com convicção (FRANSMAN, 1999). Ainda, segundo o autor, o conhecimento envolve, mas não se limita ao processamento da informação.

A seleção dessa publicação para a obtenção dos dados para análise reside em dois fatores: o primeiro, voltado à sistemática empregada na coleta dos dados, que utiliza questionário, com perguntas fechadas e diretas, a ser respondido pelos representantes das empresas, com posterior análise de consistência das informações fornecidas, essa sistemática atende ao escopo de pesquisas científicas, validando sua utilização. O segundo está relacionado às variáveis pesquisadas, que se alinham ao objetivo de verificar a gestão dos stakeholders pelas empresas, objeto de estudo desse trabalho.

Analisa-se, por meio desse estudo, a ação da organização em relação aos stakeholders abordando as seguintes práticas de gestão: a) treinamento relativo à gestão ambiental para os funcionários, para os funcionários de terceiros, para os fornecedores e para a comunidade; b) promove projetos educacionais de meio ambiente para a comunidade, de educação de meio ambiente para professores e alunos, de práticas de sustentabilidade para a comunidade, de preservação da fauna, de preservação da flora, de pesquisa voltados ao meio ambiente ou não promove projetos ambientais; c) tem ações de conscientização dos funcionários para o uso racional: da água e da energia elétrica. Como hipótese da pesquisa, pode-se inferir que as empresas certificadas pela norma NBR ISO 14001 possuem condutas diferenciadas em relação às demais, pois se pressupõem que suas estratégias devem contemplar ações ambientais voltadas aos stakeholders, condição que se estende também às empresas de grande porte, por possuírem maior visibilidade junto à sociedade. 
A tabela 1 demonstra a divisão das empresas em certificadas ou não pela norma NBR ISO 14001.

Tabela 1: Empresas certificadas ISO 14001.

\begin{tabular}{ccc}
\hline Característica da empresa & Quantidade & Percentagem \\
\hline Não Certificada ISO 14001 & 339 & $52,2 \%$ \\
Certificada ISO 14001 & 310 & $47,8 \%$ \\
Total & 649 & $100 \%$ \\
\hline
\end{tabular}

Fonte: autoria própria (2008)

A análise dos dados consiste em verificar individualmente se a gestão das variáveis pelas empresas apresenta dependência significativa por estarem ou não certificada pela NBR ISO 14001 .

O critério para definir o porte da empresa, neste estudo é o utilizado pelo Prêmio Nacional da Qualidade - FPNQ (2008), que classifica como pequenas empresas àquelas com até 50 funcionários, médias empresas entre 51 e 500 funcionários e grandes empresas, mais de 500 funcionários. Para ampliar o entendimento desse estudo, temos um grupo que compõe as pequenas e médias empresas e um segundo, apenas com as grandes empresas. Esse novo agrupamento melhora o volume quantitativo do primeiro grupo possibilitando melhor análise estatística dos dados. A tabela 2 demonstra a divisão das empresas, segundo o porte.

Tabela 2: Porte das empresas.

\begin{tabular}{ccc}
\hline Característica da empresa & Quantidade & Percentagem \\
\hline Pequeno e médio porte (até 500 funcionários) & 166 & $25,6 \%$ \\
Grande porte (mais de 500 funcionários) & 483 & $74,4 \%$ \\
Total & 649 & $100 \%$ \\
\hline
\end{tabular}

Fonte: adaptado da FPNQ (2008)

\section{Análise dos dados e resultados da pesquisa}

Os dados foram digitados no software estatístico SPSS e submetidos a análise do QuiQuadrado. Os resultados referentes à gestão ambiental dos stakeholders nas empresas, segundo a certificação ou não pela norma NBR ISO 14001, podem ser observados na tabela 3.

Tabela 3: Analise da gestão ambiental dos stakeholders frente a norma NBR ISO 14001.

\begin{tabular}{|c|c|c|c|c|c|c|}
\hline \multirow[t]{2}{*}{ Item em análise } & \multirow{2}{*}{$\begin{array}{c}\text { Condição da } \\
\text { empresa ante a } \\
\text { norma NBR } \\
\text { ISO } 14001\end{array}$} & \multicolumn{3}{|c|}{$\begin{array}{c}\text { A gestão da empresa } \\
\text { atua nessa variável de } \\
\text { controle. }\end{array}$} & \multirow{2}{*}{$\begin{array}{l}\text { Valor de } \\
\text { Pearson } \\
\text { Qui- } \\
\text { Quadrado }\end{array}$} & \multirow[t]{2}{*}{$\begin{array}{l}\text { Asymp } \\
\text { Sig (2- } \\
\text { sided) }\end{array}$} \\
\hline & & Não & $\mathrm{Sim}$ & Total & & \\
\hline \multirow{2}{*}{$\begin{array}{l}\text { Treinamento relativo à gestão } \\
\text { ambiental para os funcionários. }\end{array}$} & Não certificada & 66 & 273 & 339 & \multirow[t]{2}{*}{58,335} & \multirow[t]{2}{*}{, 000} \\
\hline & Certificada & 3 & 307 & 310 & & \\
\hline \multirow{2}{*}{$\begin{array}{l}\text { Treinamento relativo à gestão } \\
\text { ambiental para os funcionários } \\
\text { de terceiros }\end{array}$} & Não certificada & 151 & 188 & 339 & \multirow[t]{2}{*}{116,135} & \multirow[t]{2}{*}{, 000} \\
\hline & Certificada & 22 & 288 & 310 & & \\
\hline \multirow{2}{*}{$\begin{array}{l}\text { Treinamento relativo à gestão } \\
\text { ambiental para os fornecedores }\end{array}$} & Não certificada & 289 & 50 & 339 & \multirow[t]{2}{*}{63,394} & \multirow[t]{2}{*}{, 000} \\
\hline & Certificada & 177 & 133 & 310 & & \\
\hline \multirow{2}{*}{$\begin{array}{l}\text { Treinamento relativo à gestão } \\
\text { ambiental para a comunidade }\end{array}$} & Não certificada & 248 & 91 & 339 & \multirow[t]{2}{*}{8,337} & \multirow[t]{2}{*}{,004 } \\
\hline & Certificada & 194 & 116 & 310 & & \\
\hline
\end{tabular}




\begin{tabular}{|c|c|c|c|c|c|c|}
\hline \multirow{2}{*}{$\begin{array}{l}\text { Promove projetos educacionais } \\
\text { de meio ambiente para a } \\
\text { comunidade }\end{array}$} & Não certificada & 206 & 133 & 339 & \multirow[t]{2}{*}{7,605} & \multirow[t]{2}{*}{,006 } \\
\hline & Certificada & 155 & 155 & 310 & & \\
\hline \multirow{2}{*}{$\begin{array}{l}\text { Promove projetos de educação } \\
\text { de meio ambiente para } \\
\text { professores e alunos }\end{array}$} & Não certificada & 235 & 104 & 339 & \multirow[t]{2}{*}{8,413} & \multirow[t]{2}{*}{, 004} \\
\hline & Certificada & 181 & 129 & 310 & & \\
\hline \multirow{2}{*}{$\begin{array}{l}\text { Promove projetos de práticas de } \\
\text { sustentabilidade para a } \\
\text { comunidade. }\end{array}$} & Não certificada & 221 & 118 & 339 & \multirow[t]{2}{*}{2,614} & \multirow[t]{2}{*}{,106 } \\
\hline & Certificada & 183 & 127 & 310 & & \\
\hline \multirow{2}{*}{$\begin{array}{l}\text { Promove projetos de } \\
\text { preservação da fauna }\end{array}$} & Não certificada & 271 & 68 & 339 & \multirow[t]{2}{*}{3,08} & \multirow[t]{2}{*}{, 081} \\
\hline & Certificada & 230 & 80 & 310 & & \\
\hline \multirow{2}{*}{$\begin{array}{l}\text { Promove projetos de } \\
\text { preservação da flora }\end{array}$} & Não certificada & 251 & 88 & 339 & \multirow[t]{2}{*}{0,365} & \multirow[t]{2}{*}{, 546} \\
\hline & Certificada & 223 & 87 & 310 & & \\
\hline \multirow{2}{*}{$\begin{array}{l}\text { Promove projetos de pesquisa } \\
\text { voltados ao meio ambiente }\end{array}$} & Não certificada & 296 & 43 & 339 & \multirow[t]{2}{*}{8,009} & \multirow[t]{2}{*}{, 005} \\
\hline & Certificada & 245 & 65 & 310 & & \\
\hline \multirow{2}{*}{$\begin{array}{l}\text { Não promove projetos } \\
\text { ambientais }\end{array}$} & Não certificada & 196 & 143 & 339 & \multirow[t]{2}{*}{9,282} & \multirow[t]{2}{*}{,002 } \\
\hline & Certificada & 215 & 95 & 310 & & \\
\hline \multirow{2}{*}{$\begin{array}{l}\text { Tem ações de conscientização } \\
\text { dos funcionários para o uso } \\
\text { racional da água }\end{array}$} & Não certificada & 126 & 213 & 339 & \multirow[t]{2}{*}{3,386} & \multirow[t]{2}{*}{,066 } \\
\hline & Certificada & 94 & 216 & 310 & & \\
\hline \multirow{2}{*}{$\begin{array}{l}\text { Tem ações de conscientização } \\
\text { dos funcionários para o uso } \\
\text { racional da energia elétrica }\end{array}$} & Não certificada & 120 & 219 & 339 & \multirow[t]{2}{*}{6,988} & \multirow[t]{2}{*}{, 008} \\
\hline & Certificada & 80 & 230 & 310 & & \\
\hline
\end{tabular}

Fonte: autoria própria (2010)

A análise dos dados utilizando o teste do Qui-Quadrado, com significância de 5\%, demonstra que podemos rejeitar a hipótese nula nas seguintes questões: a) treinamento relativo à gestão ambiental para os funcionários e para os funcionários de terceiros, para os fornecedores e para a comunidade; b) promove projetos referentes: educacionais de meio ambiente para a comunidade, de educação de meio ambiente para professores e alunos, de pesquisa voltada ao meio ambiente; c) Tem ações de conscientização dos funcionários para o uso racional da energia elétrica. Nesse sentido, pode-se afirmar que há dependência no processo de gestão dos stakeholders pelo fato da empresa ser certificada ou não pela Norma NBR ISO 14001. Os valores obtidos demonstram que o conjunto de empresas certificadas NBR ISO 14001 pratica maior número de ações ambientais junto aos stakeholders em seu processo de gestão.

As ações de treinamento envolvendo a comunidade e os funcionários próprios, terceirizados e dos fornecedores, associadas aos projetos de Educação Ambiental para a comunidade, os professores, os alunos e as pesquisas se fazem significativamente presentes na estratégia das empresas certificadas pela norma NBR ISO 14001. Tais ações se configuram no contexto da Educação Ambiental não formal tratada na Lei /99, atuando como esforço para suprir lacunas da Educação Ambiental formal, conforme apontado por Serrano (2003). Nesse sentido, a certificação pela norma NBR ISO 14001 se integra no processo de conscientização de seus stakeholders para as questões ambientais.

A adoção de um comportamento proativo e de busca pela gestão sustentável, antecipando-se aos problemas ambientais futuros, incorpora as variáveis ambientais ao planejamento estratégico 
das empresas, posicionando-as no terceiro estágio de desenvolvimento proposto tanto por Maimon (1994) quanto por Barbieri (2007). Configura-se assim as empresas certificadas pela norma NBR ISO 14001 mais próximas das demandas ambientais da sociedade.

$\mathrm{Na}$ abordagem de promover projetos referentes à práticas de sustentabilidade para a comunidade, de preservação da fauna e da flora, e ter ações de conscientização dos funcionários para o uso racional da água não se observa essa dependência, logo não há diferença entre os grupos nesse item de análise. Essa posição demonstra baixa atuação das empresas na direção do desenvolvimento de projetos compartilhados de sustentabilidade com a comunidade.

A análise dos dados referentes à gestão ambiental dos stakeholders nas empresas, segundo o porte das organizações, pode ser observada na tabela 4 .

Tabela 4: Análise da gestão ambiental das empresas com relação ao seu porte.

\begin{tabular}{|c|c|c|c|c|c|c|}
\hline \multirow[t]{2}{*}{ Item em análise } & \multirow{2}{*}{$\begin{array}{l}\text { Condição da } \\
\text { empresa com } \\
\text { relação ao seu } \\
\text { porte }\end{array}$} & \multicolumn{3}{|c|}{$\begin{array}{l}\text { A gestão da empresa } \\
\text { atua nessa variável de } \\
\text { controle. }\end{array}$} & \multirow{2}{*}{$\begin{array}{l}\text { Valor de } \\
\text { Pearson } \\
\text { Qui- } \\
\text { Quadrado }\end{array}$} & \multirow[t]{2}{*}{$\begin{array}{l}\text { Asymp } \\
\text { Sig (2- } \\
\text { sided) }\end{array}$} \\
\hline & & Não & Sim & Total & & \\
\hline \multirow{2}{*}{$\begin{array}{l}\text { Treinamento relativo à gestão } \\
\text { ambiental para os funcionários. }\end{array}$} & Pequena + média & 29 & 137 & 166 & \multirow[t]{2}{*}{10,997} & \multirow[t]{2}{*}{, 001} \\
\hline & Grande & 40 & 443 & 483 & & \\
\hline \multirow{2}{*}{$\begin{array}{l}\text { Treinamento relativo à gestão } \\
\text { ambiental para os funcionários de } \\
\text { terceiros }\end{array}$} & Pequena + média & 48 & 118 & 166 & \multirow[t]{2}{*}{0,582} & \multirow[t]{2}{*}{, 445} \\
\hline & Grande & 125 & 358 & 483 & & \\
\hline \multirow{2}{*}{$\begin{array}{l}\text { Treinamento relativo à gestão } \\
\text { ambiental para os fornecedores }\end{array}$} & Pequena+ média & 128 & 38 & 166 & \multirow[t]{2}{*}{3,101} & \multirow[t]{2}{*}{,078 } \\
\hline & Grande & 338 & 145 & 483 & & \\
\hline \multirow{2}{*}{$\begin{array}{l}\text { Treinamento relativo à gestão } \\
\text { ambiental para a comunidade }\end{array}$} & Pequena + média & 130 & 36 & 166 & \multirow[t]{2}{*}{10,701} & \multirow[t]{2}{*}{, 001} \\
\hline & Grande & 312 & 171 & 483 & & \\
\hline \multirow{2}{*}{$\begin{array}{l}\text { Promove projetos educacionais } \\
\text { de meio ambiente para a } \\
\text { comunidade }\end{array}$} & Pequena + média & 111 & 55 & 166 & \multirow[t]{2}{*}{11,423} & \multirow[t]{2}{*}{, 001} \\
\hline & Grande & 250 & 233 & 483 & & \\
\hline \multirow{2}{*}{$\begin{array}{l}\text { Promove projetos de educação de } \\
\text { meio ambiente para professores e } \\
\text { alunos }\end{array}$} & Pequena + média & 122 & 44 & 166 & \multirow[t]{2}{*}{8,556} & \multirow[t]{2}{*}{, 003} \\
\hline & Grande & 294 & 189 & 483 & & \\
\hline \multirow{2}{*}{$\begin{array}{l}\text { Promove projetos de práticas de } \\
\text { sustentabilidade para a } \\
\text { comunidade. }\end{array}$} & Pequena + média & 123 & 43 & 166 & \multirow[t]{2}{*}{13,321} & \multirow[t]{2}{*}{, 000} \\
\hline & Grande & 281 & 202 & 483 & & \\
\hline \multirow{2}{*}{$\begin{array}{l}\text { Promove projetos de preservação } \\
\text { da fauna }\end{array}$} & Pequena+ média & 133 & 33 & 166 & \multirow[t]{2}{*}{1,084} & \multirow[t]{2}{*}{,298 } \\
\hline & Grande & 368 & 115 & 483 & & \\
\hline \multirow{2}{*}{$\begin{array}{l}\text { Promove projetos de preservação } \\
\text { da flora }\end{array}$} & Pequena + média & 130 & 36 & 166 & \multirow[t]{2}{*}{3,155} & \multirow[t]{2}{*}{, 076} \\
\hline & Grande & 344 & 139 & 483 & & \\
\hline Promove projetos de pesquisa & Pequena + média & 151 & 15 & 166 & 9,299 & ,002 \\
\hline voltados ao meio ambiente & Grande & 390 & 93 & 483 & & \\
\hline Não promove projetos ambientais & Pequena+ média & 78 & 88 & 166 & 25,644 &, 000 \\
\hline & Grande & 333 & 150 & 483 & & \\
\hline Tem ações de conscientização & Pequena+ média & 81 & 85 & 166 & 22,090 &, 000 \\
\hline $\begin{array}{l}\text { dos funcionários para o uso } \\
\text { racional da água }\end{array}$ & Grande & 139 & 344 & 483 & & \\
\hline Tem ações de conscientização & Pequena + média & 77 & 89 & 166 & 25,359 &, 000 \\
\hline $\begin{array}{l}\text { dos funcionários para o uso } \\
\text { racional da energia elétrica }\end{array}$ & Grande & 123 & 360 & 483 & & \\
\hline
\end{tabular}

Fonte: autoria própria (2010)

A análise dos dados utilizando o teste do Qui-Quadrado com significância de 5\% demonstra que podemos rejeitar a hipótese nula nas seguintes variáveis de análise, a saber: a) treinamento 
relativo à gestão ambiental para os funcionários e para a comunidade; b) promover projetos referentes à educação de meio ambiente para a comunidade e para professores e alunos, de práticas de sustentabilidade para a comunidade, de pesquisa voltada ao meio ambiente; c) tem ações de conscientização dos funcionários para o uso racional: da água e da energia elétrica. Nesse sentido, pode-se afirmar que há dependência no processo de gestão dos stakeholders do porte da empresa. Os valores obtidos demonstram que o conjunto de empresas de grande porte pratica um maior número de ações ambientais junto aos stakeholders em seu processo de gestão. Na abordagem de treinamento relativo à gestão ambiental para os funcionários de terceiros e para os fornecedores, promove projetos referentes a preservação da fauna e da flora não se observa essa dependência, logo não há diferença entre os grupos nesse item de análise. Na análise do porte da empresa se observa certa similaridade de conduta entre as empresas de grande porte e as certificadas pela norma NBR ISO 14001, com ressalva para o treinamento da gestão ambiental dos funcionários terceirizados e de fornecedores, que se posiciona com predominância para as empresas certificadas e não para as de grande porte. Isto pode se justificar, em grande parte, pela existência de requisitos que abordam essa temática na norma NBR ISO 14001.

Tanto na análise das empresas certificadas pela norma NBR ISO 14001 quanto nas de grande porte se observa predominancia das ações voltadas para ações internas em contraponto com as voltadas para o ambiente externo, refletindo maior preocupação com a eficiência das suas atividades internas do que com ações de inserção da organização no contexto da sociedade. Nesse sentido, os stakeholders, foco de atenção das empresas são aqueles responsáveis pela manutenção de suas atividades. Essa ocorrência pode ser explicada pela norma NBR ISO 14001 (ABNT, 1996) que estabelece o requisito de treinamento para todos os funcionários e prestadores de serviços cujas tarefas possam provocar impacto significativo sobre o meio ambiente.

Os dados apontam a existência de ações socioambientais voltadas para os stakeholders nas organizações, mas com predominância do foco de atenção em seu público interno, o que demonstra que as empresas se posicionam em evoluído estágio de desenvolvimento, conforme propostas de Maimon (1994) e Barbieri (2007), mas ainda não atingiram o patamar apontado como pleno por Rohrich e Cunha (2004), em que se incorpora tanto o contexto da empresa quanto o da sociedade.

\section{Considerações finais}

Este artigo se propôs a verificar se as empresas com Sistema de Gestão Ambiental certificadas com a norma NBR ISO 14001 e as de maior porte incorporam os stakeholders na gestão empresarial, de forma mais acentuada do que as que não são certificadas pela norma ambiental.

Os dados apontam que as empresas certificadas pela norma NBR ISO 14001 demonstram 
uma maior atenção com relação aos stakeholders, pois dos 13 itens 9 (69,2\%) foram objeto de análise. Observou-se essa predominância, condição esta justificável em decorrência da necessidade de contemplar as questões ambientais de acordo com a estratégia estabelecida, conforme demanda o processo de certificação pela referida norma. Esse mesmo desempenho é observado quando são analisadas as empresas, conforme seu tamanho. Nesse sentido, as empresas de maior porte apresentam um comportamento mais voltado a atuar ambientalmente junto a seus stakeholders do que as empresas de pequeno e médio porte. Nessa análise, houve a ocorrência predominante de 9 $(69,2 \%)$ itens de um total de 13.

A maior presença de ações de treinamento para a abordagem socioambiental nas empresas detentoras da certificação pela norma NBR ISO 14001, demonstra a preocupação em atendimento aos requisitos da norma, em particular para o treinamento, a conscientização e o desenvolvimento das competências. O não atendimento desses requisitos pelas empresas certificadas pode desencadear na não manutenção de sua respectiva certificação.

A limitação desse estudo, reside no fato de ter se desenvolvido com uma base de dados secundária, condição essa que limita os autores na dinâmica de estabelecer suas estratégias tanto de definição quanto de coleta de dados. Essa limitação restringe os autores na expansão do escopo da pesquisa, porém sem comprometer as conclusões obtidas.

$\mathrm{O}$ acréscimo da preocupação com os stakeholders externos à organização, associada à evolução da gestão ambiental da empresa, conforme demonstrado na parte teórica, faz com que as empresas apresentem diferentes níveis evolutivos de gestão ambiental, e somente em estágios mais desenvolvidos, surge à preocupação com os componentes externos a empresa. Assim, para futuros estudos recomendam-se pesquisas para verificar a relação entre o tempo de certificação pela norma ambiental NBR ISO 14001 e a incorporação de stakeholders externos, no que tange aos aspectos da gestão ambiental das empresas.

\begin{abstract}
The environmental worry is presented as a theme in the discussions and reflections of society, public authorities and organizations. Awareness and understanding of the importance of the environment by society, demands the need for actions that provide a set of knowledge regarding this topic. Thus highlights the importance of environmental education as a component of the conformation of a society that incorporates the environmental dimension, with the bases of its economy governed by sustainability. In this context, the objective of this research is check if the companies with the Environmental Management System certified to ISO 14001 incorporates the stakeholders in corporate governance most strongly that companies not certified by the environmental standard. This descriptive search on a sample of 649 companies that provided information for publication in the journal "Análise Gestão Ambiental" (2008). The use of statistical analysis that showed that companies certified by NBR ISO 14001 demonstrate the presence of a larger set of environmental factors directed to the stakeholders.
\end{abstract}

Key-words: environment; environmental education; environmental management; ISO 14001; stakeholders. 


\section{Referências}

ANÁLISE GESTÃo AMBIENTAL. São Paulo: Análise Editorial, 2008.

ASSOCIAÇÃO BRASILEIRA DE NORMAS TÉCNICAS (ABNT). NBR ISO 14001: Sistemas de gestão ambiental requisitos com orientação para o uso. Rio de Janeiro, 2004.

BARBIERI, J. C. Gestão ambiental empresarial. São Paulo: Saraiva, 2007.

BOURNE, L.; WALKER, D. H. T. Visualizing and mapping stakeholder influence. Management decision. V. 43, n 5, p 649-60, 2005.

cross ${ }^{\text {ref }}$

BRASIL. Constituição da Republica Federativa do Brasil, 1988.

. LEI No 9.795. Dispõe sobre a Educação Ambiental, institui a Política Nacional de Educação Ambiental e dá outras providências. 1999.

CERVO, A. L.; BERVIAN P. A.; SILVA R. Metodologia científica. 6. ed. São Paulo: Pearson Prentice Hall, 2007.

DIAS, G.F. Educação Ambiental: princípios e práticas. São Paulo, Gaia, 1992.

DONAIRE, D. Gestão ambiental nas empresas. 2.ed. São Paulo. Atlas, 1999.

FERREIRA, L. C. Idéias para uma sociologia da questão ambiental no Brasil. São Paulo: Ed. AnnaBlume, 2005.

FPNQ. Critérios de excelência: o estado da arte da gestão para a excelência do desempenho 2004. São Paulo: Publicado por FPNQ Fundação para o Prêmio Nacional da Qualidade, 2008.

FRANCO, T. Padrões de produção e consumo nas sociedades urbano-industriais e suas relações com a degradação da saúde e do meio ambiente. In MINAYO, M. C. de S. (org.). Saúde e ambiente sustentável: estreitando nós. Rio de Janeiro: FIOCRUZ, 2002.

FRANSMAN, M. Vision of innovation: the firm and Japan. Nova York: Oxford University Press Inc., 1999.

FRYXELL G.E.; SZETO, A. The influence of motivations for seeking ISO 14001 Certification: an empirical study of ISO 14001 certified facilities in Hong Kong. Journal of Environmental Management, v. 65, n 3, p 223-238, 2002.

cross ${ }^{\text {ref }}$

MAIMON, D. Eco-estratégia nas empresas brasileiras: realidade ou discurso? Revista de Administração de Empresas-RAE, São Paulo, v. 34, n. 4, p. 119-30, 1994.

ROHRICH, S. S.; CUNHA, J. C. A proposição de uma taxonomia para a análise da gestão ambiental no Brasil. Revista de Administração Contemporânea, São Paulo, v. 8, n. 4, p. 86-95, 2004.

ROSEN, C. M. Environmental strategy and competitive advantage: an introduction. California Management Review, v. 43 , n. 3, p. 9-20, 2001.

SAVAGE, G. T. et al. Strategies for assessing and managing organizational stakeholders. Academy of Management Executive, V.5, n 2, p 61-75. 1991.

SEIFFERT, M. E. B. ISO 14001: sistemas de gestão ambiental. São Paulo: Atlas, 2005.

SERRANO, C. M. L. Educação Ambiental e consumerismo em unidades de ensino fundamental de Viçosa-MG. 2003. 91 p. Dissertação (Mestrado em Ciência Florestal) - Universidade Federal de Viçosa, Viçosa, 2003.

SLACK, N. et al. Administração da produção. São Paulo: Atlas, 2002.

TAPSCOTT, D., ; TICOLL, D. A empresa transparente. São Paulo: M. Books do Brasil. 2005. 
ZENG, S. X. et al. Towards implementation of ISO 14001 environmental management systems in selected industries in China. Journal of Cleaner Production, v. 13, n. 7, p. 645-656, 2005.

crossef

\section{Nome: Celso Machado Junior}

Filiação institucional: Universidade Municipal de São Caetano do Sul - USCS

Departamento: Escola de Negocios

Função ou cargo ocupado: Professor mestre

Endereço completo: Rua General Lecor 367, apto 122 Ipiranga, Sao Paulo, SP, Brasil, CEP

04213.020

Telefones de contato: Celular: (11) 9851.4242 / Residencial: (11) 2068.5826

e-mail: celsomachado1@gmail.com

Nome: Maria Tereza Saraiva de Souza

Filiacao institucional: Universidade Nove de Julho

Departamento: Professor do Programa de Mestrado e Doutorado - PMDA

Função ou cargo ocupado: Professor doutor

Endereço completo: Alameda Ministro Rocha Azevedo, 644 - apto 43, Jardim Paulista - São Paulo, Brasil, CEP: 01410-000

Telefones de contato (11)99907997/ (11)3061-0551/ (11) 3665-9342

e-mail:mtereza@uninove.br<mailto:mtereza@uninove.br>

Nome: Cristiane Jaciara Furlaneto

Filiação institucional: Universidade Municipal de São Caetano do Sul - USCS

Departamento: Escola de Saúde

Função ou cargo ocupado: Professor doutor

Endereço completo: Rua General Lecor 367, apto 122 Ipiranga, Sao Paulo, SP, Brasil, CEP

04213.020

Telefones de contato: Celular: (11) 95707287 / Residencial: (11) 2068.5826

e-mail: crisjaciara@ig.com.br

Nome completo: Leonel Mazzali

Filiacao institucional - Universidade de São Caetano do Sul - USCS

Departamento: Professor do Programa de Mestrado e Doutorado - PMDA

Função ou cargo ocupado: Professor doutor

Endereço completo - Rua João Antonio de Campos, 40, Jundiaí-SP , Brasil, CEP 13209-280

Telefones de contato - 011 7093- 9001

e-mail-leonel_mazzali@uol.com.br

Nome completo: João de Paula Ribeiro Neto

Filiação institucional: Universidade Municipal de São Caetano do Sul - USCS

Departamento: Escola de Negocios

Função ou cargo ocupado: Professor

Endereço: Rua Plínio de Morais, 33, Perdizes, São Paulo - SP, Brasil, CEP: 01252-030

Telefones de contato: (11) $99555654 \mathrm{cel} /$ (11) $38632075 \mathrm{res} /$ (11) $42393296 \mathrm{com}$

e-mail:joao.ribeiro@uscs.edu.br

Enviado em:24/03/2010

Aprovado em:10/03/2011 